\title{
TPF Regimen
}

National Cancer Institute

\section{Source}

National Cancer Institute. TPFRegimen. NCI Thesaurus. Code C63683.

A regimen consisting of docetaxel, cisplatin and fluorouracil used for the treatment of squamous cell head and neck cancer and gastric cancer. 